\title{
INTERMEDIAÇÃO TECNOLÓGICA E EDUCAÇÃO AMBIENTAL UTILIZANDO METODOLOGIAS ATIVAS DE APRENDIZAGEM NA EDUCAÇÃO BASICA DA BAHIA
}

\author{
SALVADOR/BA JUNHO/2018
Graça Regina Armond Matias Ferreira - UFBA/CEMITEC/SEC/BA - ginamatias@hotmail.com Marco Antonio Leandro Barzano - UEFS - ginamatias@hotmail.com
Sandra Lúcia Pita de Oliveira Pereira - UFBA/CEMITEC/BA - sandrapita@uol.com.br

Tipo: Investigação Científica (IC)

Natureza: Planejamento de Pesquisa

Categoria: Métodos e Tecnologias

Setor Educacional: EDUCAÇÃO INFANTIL E FUNDAMENTAL, EDUCAÇÃO MÉDIA E TECNOLÓGICA

\begin{abstract}
RESUMO
A facilitação do acesso às informações por intermédio das tecnologias de aprendizagem na educação tem estimulado os alunos em diferentes ambientes pedagógicos, permitindo uma ampliação no que tange a aprendizagem das ações socioambientais, permitindo uma imersão da comunidade nos problemas que envolvem o seu entorno, de uma maneira mais ativa, em diferentes níveis e modalidades de ensino. O uso das metodologias ativas na educação como forma de promover um protagonismo juvenil é um conceito recente atrelado às práticas inovadoras que envolvem o currículo, mas utilizado apenas na educação superior, sendo pouco discutida e investigada na educação básica, principalmente em se tratando de alunos da zona rural e comunidades tradicionais. Partindo desse problema levantado, este trabalho objetiva apresentar alguns resultados de experiências pedagógicas com ações de sustentabilidade ambiental utilizando a aula de campo como ferramenta problematizada na educação básica da rede pública da Bahia, através do uso da intermediação tecnológica como mediação nas aulas de ciências da natureza no ensino médio da rede pública de ensino, utilizando para isso ferramentas que envolvem uma experimentação ativa de aprendizagem de maneira interdisciplinar. A metodologia envolvida tem uma perspectiva qualitativa através da pesquisa narrativa de atividades pedagógicas que envolvem metodologias ativas na vertente Educação Ambiental, tendo com participantes professores, mediadores e alunos do EMITEC (Ensino Médio com Intermediação Tecnológica), no período de 2015 a 2017. Os resultados dessas pesquisas revelam que é possível realizar esse tipo de interação com os alunos neste tipo de modalidade, e que o envolvimento e aprendizagem se tornam mais eficientes quando relacionados de forma interdisciplinar partindo do protagonismo e respeitando a pluralidade cultural para uma aprendizagem significativa.
\end{abstract}

Palavras-chave: Educação Ambiental; Metodologias Ativas; Intermediação Tecnológica.

\section{AGRADECIMENTOS}

AO MEU ORIENTADOR MARCO ANTONIO LEANDRO BARZANO POR TODO APOIO E ORIENTAÇÃO. 


\section{Introdução}

$\mathrm{Na}$ educação e, particularmente em se tratando em educação no ensino de ciências naturais, a prática escolar é caracterizada como tradicional, isto é, baseada ainda em um modelo de transmissão e recepção de conteúdos curriculares que afastam o aluno do processo de construção do conhecimento, transformando-os em indivíduos sem condições, muitas vezes, de criar, pensar reflexivamente, de construir conhecimentos novos e reconstruir conhecimentos já sistematizados (MORAES, 2007). No cenário educacional contemporâneo, as dificuldades enfrentadas na área de ciências da natureza, são latentes e de toda ordem, principalmente na modalidade de ensino médio a distância.

O grande desafio do educador na contemporaneidade é tornar o ensino de Biologia prazeroso e instigante sendo capaz de desenvolver no aluno o saber científico. Segundo Krasilchik (2005), verifica-se que é unânime entre os educadores a consciência de que o ensino exclusivamente informativo, centrado no professor, está fadado ao fracasso, estabelecendo-se um clima de apatia e desinteresse, que impede a interação necessária ao verdadeiro aprendizado. Os processos de ensino e aprendizagem devem ser dinâmicos e multidirecionais gerando a necessidade de criação de mecanismos de construção diferentes dos tradicionalmente utilizado nas escolas. Esses provocam uma série de problemas agravados na medida em que os alunos, muitas vezes, não encontram significado nas aulas que são obrigados a frequentar. Neste sentido, é preciso buscar/pensar soluções tecnológicas que promovam o estímulo nos alunos, deixando as aulas mais motivadoras e interessantes para o público do Ensino Médio na maior parte das vezes, formada por adolescentes que vivenciam as tecnologias em outros campos da vida social, não fazendo uma relação com os conteúdos curriculares vistos nas escolas (SILVA, 2015; FERREIRA, 2012; 2013; 2014).

A exemplo disso Krasilchik nos diz que embora as atividades dentro da escola podem propiciar aprendizagens significativas, as atividades fora do ambiente escolar, no seu entorno, em contato direto com a realidade e as características da sua região para problematizar a aprendizagem pois "quanto mais as experiências educativas se assemelharem às futuras situações em que os alunos deverão aplicar seus conhecimentos, mais fácil se tornará a transferência do aprendizado" (KRASILCHIK, 2008, p. 131). Partindo desta análise, a utilização dessas ferramentas é um espaço aberto para discussões e experimentações envolvendo o uso integrado das tecnologias e conteúdos curriculares de meio ambiente e educação ambiental (FREIRE, 2002; ARANHA, 2006; JENKINS, 2008; MORAN, 2005; BARZANO, 2008), promovendo a união entre aprendizagem, experimentação ativa e ludicidade com o uso de soluções 
tecnológicas que possibilitem a realização das mesmas pela intermediação tecnológica na rede pública de ensino e EaD que emerge na sociedade atual como uma modalidade relevante e promissora (LITTO e FORMIGA, 2011).

Em 2011 o governo do estado da Bahia, por meio da Secretaria da Educação, lançou o programa Ensino Médio com Intermediação Tecnológica- EMITec, que se constitui em alternativa pedagógica para atender a três vertentes desafiadoras da educação baiana: a extensão territorial constituída por 417 municípios, a carência de docentes habilitados em localidades longínquas e a necessidade de articular o que acontece no mundo com os acontecimentos regionais e locais desses espaços, com o intuito de auxiliar na construção da cidadania, bem como atenuar as desigualdades socioculturais no nosso Estado. Esse programa tem sido alternativo de muitos alunos, de diferentes culturas, tais como quilombolas, ribeirinhos, indígenas pertencentes em diferentes localidades, com costumes e culturas próprias, não tendo a necessidade de sair de sua região de origem para concluir seus estudos.

Sendo assim, neste trabalho consideramos essas atividades como metodologia ativa que é descrita como uma concepção educacional que coloca os alunos como principais agentes de seu aprendizado, onde o estímulo a crítica e reflexão é incentivado pelo professor que conduz a aula, mas o centro desse processo é o aluno; podendo trabalhar o aprendizado de uma maneira mais participativa e fluída, utilizando ferramentas e estratégias de ensino, no contexto de conteúdos de educação ambiental, tais como: aprendizagem baseada em projetos; problematização e reflexão sobre experiências realizadas; aula de campo; simuladores de realidade aumentada e virtual; jogos interativos e/ou eletrônicos; atividade gamificada; mapa conceitual; estudo dirigido; aprendizagem baseada em problemas, dentre outras que permitem que o aluno possa experimentar na prática o fazer ciências, permitindo imergir no conteúdo e praticar assim, a aprendizagem significativa.

\section{Objetivo}

Este artigo teve como objetivo demonstrar as possibilidades de inclusão de práticas pedagógicas educativas no ensino de ciências da natureza, na modalidade $\mathrm{EaD}$, através da intermediação tecnológica, trabalhando com as aulas de campo, respeitando o currículo do ensino médio da educação básica, utilizando-se para isso processos tecnológicos utilizados no Programa EMITEC/BA.

\section{Metodologia}


A metodologia utilizada neste trabalho foi a pesquisa-ação e análise das narrativas, incluindo relatos orais e depoimentos nos chats e fóruns, que vem sendo bastante difundida e utilizada dentro da pesquisa educacional. Buscando atingir o objetivo proposto baseada na escolha da lente teórica, planejamento, execução e acompanhamento avaliativo dos instrumentos de enfoque nos conteúdos de educação ambiental no currículo do EMITEC, buscou-se responder a seguinte questão geral: as práticas pedagógicas utilizadas nas aulas de ciências naturais têm contribuído de forma crítica, ativa e reflexiva, na aprendizagem em educação ambiental?

O trabalho foi realizado com alunos e professores do EMITEC, matriculados no ano de 2016 e 2017 na $2^{\text {a }}$ série do ensino médio, dentro dessa metodologia. A matriz curricular bem como os conteúdos transmitidos foi pautada nos documentos oficiais do Ministério da Educação e nos eixos estruturantes e objetivos de aprendizagem da Base Nacional Comum Curricular- BNCC. As aulas ao vivo ocorreram em escolas/pólo municipais, na presença de um mediador, de maneira presencial, mediadas pela tecnologia à distância por meio de plataformas modernas de telecomunicações, que inclui possibilidades de videoconferência e acesso simultâneo à comunicação interativa entre usuários empregando IP (Internet Protocol) por satélite VSAT (Very Small Aperture Terminal), através do IPTV (Internet Protocol Television), bem como de materiais didáticos utilizando a plataforma moodle. As aulas, em cada disciplina, são geminadas e divididas em tempos pedagógicos complementares [exposição, produção e interação]. Sobre como utilizar esses últimos tempos pedagógicos, é que esse trabalho focou, buscando a inserção de atividades experimentais inovadoras, ditas metodologias ativas, durante as aulas que foram relacionadas ao contexto de Meio Ambiente e Educação Ambiental, formando assim uma rede de investigação e colaboração de processos que envolvem as inovações educacionais através de uma experimentação científica e ensino de ciências.

Através desse ambiente é realizado o contato com os mediadores atuantes, acesso às aulas gravadas, material de apoio pedagógico, construído pelos professores de cada disciplina, bem como lista de exercícios, atividades, avaliações e outros suportes pedagógicos. Nele também é feito o contato dos mediadores com toda a equipe pedagógica e docente do programa. Foram utilizados, em diferentes momentos, o instrumento de coleta de dados, através da observação direta dos chat e análise das narrativas dos alunos, mediadores e dos professores e que são tradicionalmente utilizadas em pesquisas qualitativas; além do trabalho de campo de coleta de informações e planejamento de oficinas com os professores e alunos.

O principal repositório, objeto de investigação, foi o Ambiente Virtual de Aprendizagem (AVA), onde estão disponíveis os Planos de Ensino, Manuais e as aulas gravadas; outro 
elemento procedimental foram as interações no ambiente através do chat e das "webconferências" ao vivo, realizadas durante as aulas, onde conseguimos acompanhar as narrativas dos docentes e discentes participantes, validando o uso dessas práticas pedagógicas inovadoras no ensino Meio Ambiente/Educação Ambiental.

\section{Resultados e Discussão}

Sabendo que no ensino de ciências naturais, em especial as aulas de ciências e biologia ou disciplinas que envolvem o estudo de meio ambiente e educação ambiental, as aulas de campo são um instrumento eficiente para o estabelecimento de uma nova perspectiva na relação entre o homem e a natureza. Trilhas interpretativas em unidades de conservação são excelentes práticas educativas, que envolvem metodologias ativas, em que o aluno aprende sobre a dinâmica dos ecossistemas, tornando-o mais apto a atuar e decidir sobre os problemas ambientais e sociais da sua realidade.

Segundo SANTOS (2002), as contribuições da aula de campo de Ciências e Biologia em um ambiente natural podem ser positivas na aprendizagem dos conceitos à medida que são um estímulo para os professores, que veem uma possibilidade de inovação para seus trabalhos e assim se empenham mais na orientação dos alunos. Para os alunos é importante que o professor conheça bem o ambiente a ser visitado e que este ambiente seja limitado, no sentido espacial e físico, de forma a atender os objetivos da aula. Neste trabalho, o lúdico foi utilizado para estudar a ecologia, a diversidade animal e vegetal bem como as interações entre os indivíduos, que foram separadas em subcapítulos para apresentação e discussão desta experiência interdisciplinar.

Esse procedimento despertou maior interesse por parte dos alunos sobre estes temas que muitas vezes é trabalhado, pelos professores de ciências com a finalidade de memorização de conceitos ou como uma mera atividade de vivencia externa, não acionando o protagonismo e a valoração cultural dos diferentes ambientes, relacionados a percepção do ambiente. Esse interesse tem como consequência uma real aprendizagem que pode modificar condutas importantes, relacionada com a Ecologia e Interação homem e ambiente, levando a modificações na qualidade de vida dos estudantes, promoção de ações socioeducativas e socioambientais e de toda a comunidade em que ele está inserido.

\section{Solução Tecnológica em EaD através de Práticas Educativas: Relato do Parque Lagoa das Dunas}

A inserção da aula externa para as aulas de Biologia trouxe ótimas oportunidades do 
ponto de vista pedagógico, pois proporciona "[...] complementar, desenvolver e transformar as ideias, teorias e conhecimentos que os alunos trazem, desmistificando a distância entre o mundo da ciência e o mundo do cotidiano" (SANTOS, 2011). Assim, este instrumento pedagógico transforma-se em um momento de grande aprendizado para o professor onde ele tem a oportunidade de perceber a utilização de alguns conteúdos teóricos trabalhados na disciplina, além de valorizar o trabalho docente.

Pode-se perceber que a utilização desta ferramenta tecnológica em questão é uma grande oportunidade de aprendizado tanto para os estudantes quanto para os professores. Portanto, a aula externa torna-se um importante auxiliar para contextualizar os assuntos abordados nas aulas semanais ocorridas nos estúdios, permitindo que o aluno ultrapasse a barreira do conteúdo teórico e perceba a utilização daquele tema no cotidiano. Além disso, amplia a variedade de metodologias utilizadas na aula, proporcionando um aprendizado significativo.

No primeiro momento foi realizado, na entrada do Parque, a apresentação do local de gravação, dando importância a APA e trazendo conceitos de área, clima, vegetação e animais da região, levando o aluno a refletir sobre a importância da conservação de um bioma de restinga em área urbana. Neste aspecto, podemos aplicar a qualquer outro ecossistema de vivência do aluno, levando aspectos exploratórios, indicando a importância deste tipo de trabalho para o entendimento de diferentes conceitos dentro da disciplina de Biologia voltados ao currículo do ensino médio.

Durante da elaboração deste recurso tecnológico, foi sistematizado temas dentro do mesmo ambiente que poderão ser explorados por diferentes conteúdos atrelados ao currículo escolar bem como servir de agente norteador ao currículo flexível de cada localidade a depender do bioma da região na qual está inserido, partindo do princípio de aprendizagem de educação ambiental interdisciplinar. Nesta gravação, subdividimos através dos seguintes conteúdos, que foram explorados em diferentes contextos dentro das temáticas diversificadas da área de ciências naturais:

\section{Análise das narrativas dos alunos e mediadores: chat e fórum}

Durante a execução das aulas foram acompanhadas as interações dos alunos durante a exposição onde as questões sobre a diversidade ambiental, conservação e problemas ambientais foram problematizadas demostrando a percepção local, quando comparadas aos problemas locais que estavam sendo vivenciados por eles em suas localidades. Através do convite as trilhas interpretativas realizadas através da gravação dessas aulas, os principais questionamentos, envolveram questões de biodiversidade, 
biogeografia e impactos antrópicos. Durante as exposições dos questionamentos dos alunos, percebemos a integração entre as disciplinas, naturalmente, vivenciadas em ambientais rurais, que permeiam as atividades interativas e metodologias ativas como uma ferramenta interdisciplinar.

No início da aula foi questionado sobre a importância ambiental e ao final foram exibidos alguns trechos dos vídeos construídos pelos alunos nas turmas anteriores, permitindo um reconhecimento e acompanhamento do entorno, onde eles reconheciam o local e discorriam como estava aquele ambiente na atualidade, e divulgados nos fóruns de aprendizagem das diferentes disciplinas, que é o contato entre os professores e mediadores de diferentes localidades.

As participações e questionamentos dos alunos foram mediados e acompanhadas através dos chats pelo professor assistente e mediados e respondidos pelo professor de vídeo, onde as interações são debatidas ao vivo durante as aulas, permitindo um amplo diálogo entre todas as comunidades envolvidas, através de uma interação e percepção de sua região, onde sensivelmente conseguimos perceber a valoração local ao discorrer sobre as suas descrições realizadas em tempo real entre os alunos.

Já as narrativas feitas pelos mediadores nos fóruns, costumam ser mais diretas e simples, quando relacionadas a postagens de atividades, que são opcionais, nas disciplinas, percebemos uma simplicidade e poucos argumentos para descrever as mesmas, por se tratar de atividades feitas pelos alunos, e que de maneira geral eles demostraram que os meninos gostam desse tipo de atividade, que permite acompanhar os desenvolvimentos nas aulas de ciências naturais.

No momento em que as narrativas são mais fortes, são nas aulas interdisciplinares, realizadas entre os componentes das disciplinas da área com um tema especifico que os alunos desenvolvem atividades ativas dentro da sua localidade, de forma artística, cultural e expositiva, permitindo a integração dos saberes entre os diferentes conteúdos trabalhados nas aulas. Nessas produções a questão ambiental é bem forte, e as ações voltadas a melhora da qualidade de vida e estimulo a aprendizagem, valorizando e cuidando do ambiente local de forma sustentável e criativa.

\section{Considerações Finais}

Diante dos resultados apresentados, em turmas do ensino médio com intermediação tecnológica, demonstra-se que a inserção, investigação e o aprimoramento de aulas diversificadas em formas de metodologias ativas traz uma solução possível para 
despertar 0 interesse dos alunos, está na inovação e diversificação das práticas escolares. Estas deixariam de ser centradas em ações rotineiras e conteudistas, e utilizariam estratégias motivadoras e lúdicas que valorizem o saber científico, convidando o estudante a buscar mais informações além daquelas apresentadas em sala de aula, motivando assim o uso de aulas práticas, aqui compreendidas como práticas educativas inovadoras. Sendo assim, os relatos aqui apresentados são relevantes como mecanismo de promoção do conhecimento e solução tecnológica, como também de desenvolver práticas em ciências naturais no contexto da educação ambiental, bem como outros contextos de aprendizagem. Sabendo-se da importância da aprendizagem significativa para a educação básica, percebe-se a relevância do relato ora descrito, não apenas como estratégia de diversificação das aulas, mas como uma ferramenta de educação ativa para que, atingindo os alunos no presente momento, levando-o a atuar como agente multiplicador dessa ação dentro da sua comunidade, propiciando um aprendizado significativo, revelando mais uma ação socioambiental eficaz para a garantia do exercício pleno para a efetiva cidadania.

A possibilidade de inserção de metodologias ativas na educação básica se torna um meio possível e abrangente, propiciando uma exploração mais aprofundada no contexto da intermediação tecnológica, envolvendo também estudos com alunos de zona rural e comunidades culturalmente ricas, que envolvem as tecnologias, possibilitando uma autonomia e vivencia de multimeios para uma efetiva aprendizagem. Vale ressaltar que este relato é uma motivação para o início de um trabalho de pesquisa e parte da nossa investigação de doutorado no ensino de ciências, onde diferentes ferramentas pautadas na experimentação e metodologias ativas, estão sendo estudadas de forma a atrelar o currículo e a educação no ensino de ciências, como parte do contexto ambiental tratada como forma interdisciplinar, também na educação no meio rural, onde as diversas narrativas serão mais estimuladas ao decorrer da pesquisa, motivando e estimulando a realização de diferentes pesquisas e estudos que investiguem de forma mais aprofundada as interações e vivencias objetivadas na aprendizagem significativa.

\section{Referências}

ARANHA, G. Jogos eletrônicos como um conceito chave para o desenvolvimento de aplicações imersivas e interativas para o aprendizado. Ciência e Cognição, v. 17, p. 105-110, 2006.2 Disponível em: $<$ http://www.cienciasecognicao.org/pdf/v07/m31685.pdf>. Acesso em: 15/10/2009.

BARZANO, Marco Antonio Leandro. Educação não-formal: Apontamentos ao Ensino de Biologia. In: Ciência em Tela, v(1). 2008 
BRASIL, Ministério da Educação. Secretaria de Educação Média e Tecnológica. PCN+ Ensino Médio: orientações educacionais complementares aos Parâmetros Curriculares Nacionais: Ciências da Natureza, Matemática e suas Tecnologias. Brasilía, DF: MEC, 2002.

BRASIL. Lei de Diretrizes e Bases da Educação Nacional. Lei oㅜ 9.394, de 20 de dezembro de 1996. Estabelece as diretrizes e bases da educação nacional. Brasília:MEC, 1996.

FERREIRA, Graça Regina; LIMA, Mônica Moreau; JESUS, Rosana Sales. Uso de Paródias no Ensino e Aprendizagem em Biologia. [51 -63] Capítulo de Livro. In: SANTOS, Letícia Machado dos (Org.) Educação Básica com Intermediação Tecnológica: tendências e práticas. Volume 01. Prefácio. 2012.

FERREIRA, Graça Regina Armond Matias ; LIMA, M. M. C. ; JESUS, R. S. Uso de Paródias no Ensino e Aprendizagem em Biologia. In: Letícia Machado dos Santos. (Org.). Educação Básica com Intermediação Tecnológica: tendências e práticas. 1ed.Salvador: Fast Design - Visual Editora e Gráfica Rápida Ltda., 2012, v. 1, p. 51-63.JENKINS, H. Cultura da Convergência. São Paulo: Aleph, 2008.

FERREIRA, G. R. A. M.; SANTOS, L. M. ; PINHEIRO, N. S. G. ; PITA, Sandra Lúcia . Relatos de Experiências de Práticas Exitosas nas Aulas de Ciências da Natureza e suas Tecnologias. In: Letícia Machado dos Santos. (Org.). Educação Básica com Intermediação Tecnológica: tendências e práticas . 01ed.Salvador: Fast Designer, 2014, v. 02 , p. $43-53$.

LITTO, F. FORMIGA, M. (Org.). Educação a Distância: o estado da arte. Volume 02. Editora Pearson. 2011

KRASILCHIK, M. Prática de Ensino de Biologia 4. ed. São Paulo: Editora Universidade de São Paulo, 2005.

KRASILCHIK, M. Novas Práticas de ensino de Biologia. São Paulo, Editora da Universidade de São Paulo, 2008.

MORAES, Maria Cândida. O paradigma educacional emergente. 13.ed. Campinas/BR: Papirus, 2007. (Coleção “Práxis”). ISBN 85-308-0478-3.

PACHECO, Éser \& SILVA, Hilton P. Compromissos Epistemológicos do Conceito de 
Percepção Ambiental. Rio de Janeiro: Departamento de Antropologia, Museu Nacional e Programa EICOS/UFRJ, 2007

SANTOS, S. A. M. A excursão como recurso didático no ensino de biologia e educação ambiental. In: VIII ENCONTRO PERSPECTIVAS DO ENSINO DE BIOLOGIA, 6, 2002, São Paulo.Anais... São Paulo: FEUSP, 2002. 1 CD-ROM

SILVA, D. M. V. ; FERREIRA, G. R. A. M. ; FON, I. R. S. ; CUNHA, M. M. ; JESUS, R. S. . Luz, Câmera e Ação! O uso pedagógico da aula externa como recurso tecnológico no ensino de Biologia. In: Letícia Machado dos Santos. (Org.). Educação Básica com Intermediação Tecnológica: tendências e práticas. 01ed.Salvador: Fast Designer, 2015, v. 03 , p. $129-138$

UNIDUNAS. Universidade Livre das Dunas e Restinga de Salvador. 2015 